\section{Template boundary definition in mammalian telomerase}

\author{
Jiunn-Liang Chen and Carol W. Greider ${ }^{1}$ \\ Department of Molecular Biology and Genetics, Johns \\ Hopkins University School of Medicine, \\ Baltimore, Maryland 21205, USA
}

Telomerase uses a short template sequence in its intrinsic RNA component to synthesize telomere repeats. Disruption of the helix P1b in human telomerase RNA or alteration of its distance from the template resulted in telomerase copying residues past the normal template boundary both in vivo and in vitro. Therefore, helix P1b is important for template boundary definition in human telomerase. Mouse telomerase RNA lacks helix P1b, and the boundary is established at 2 nt downstream of the 5 '-end. The divergent structure of boundary definition elements in mammals, yeast, and ciliates suggests diverse mechanisms for template boundary definition in telomerase.

Received August 4, 2003; revised version accepted September 16, 2003.

Eukaryotic chromosome stability requires telomere maintenance by telomerase (Greider and Blackburn 1985). Telomerase, a unique reverse transcriptase, maintains telomeres by adding telomeric repeats to chromosome ends to counterbalance the shortening during DNA replication (Greider 1996). Telomerase is active in many human tumor cells, but not in normal somatic cells (Kim et al. 1994). The human diseases dyskeratosis congenita and aplastic anemia are associated with mutations in the conserved regions of human telomerase RNA (Vulliamy et al. 2001, 2002). To fully understand the molecular mechanisms that underlie these diseases, it is essential to understand the structure and function of telomerase.

The telomerase enzyme consists of two essential core components, the catalytic protein component, telomerase reverse transcriptase (TERT), and the telomerase RNA (TR) that specifies the repeat sequence added (Greider and Blackburn 1989|. The TERT protein component contains conserved motifs that constitute the enzyme active site (Lingner et al. 1997). A putative RNA-binding domain within the $\mathrm{N}$-terminal region of the protein is important for telomerase RNA binding in ciliate and mammalian telomerase complexes (Bryan et al. 2000; Lai et al. 2001). The TERT protein and the telomerase RNA are sufficient to reconstitute telomerase activity in vitro (Weinrich et al. 1997; Beattie et al. 1998).

Telomerase RNAs are extremely divergent in se-

[Keywords: Telomerase; RNA; template; reverse transcriptase; ribonucleoprotein]

${ }^{1}$ Corresponding author.

E-MAIL cgreider@jhmi.edu; FAX (410) 614-2987.

Article and publication are at http://www.genesdev.org/cgi/doi/10.1101/ gad.1140303. quence and in length. Telomerase RNAs from ciliates are small (148-209 nt) and have a conserved secondary structure (Romero and Blackburn 1991; Lingner et al. 1994). In contrast, yeast telomerase RNAs are significantly larger (930-1544 nt; Tzfati et al. 2000). The vertebrate telomerase RNAs range in size between 382 and $559 \mathrm{nt}$ and have a conserved secondary structure /Chen et al. 2000, 2002). The secondary structure of vertebrate RNA consists of four highly conserved structural domains: the pseudoknot, CR4-CR5, box H/ACA, and CR7 domains. The pseudoknot and CR4-CR5 domains can independently assemble with TERT protein and are essential for telomerase activity in vitro (Tesmer et al. 1999; Mitchell and Collins 2000; Chen et al. 2002). The box $\mathrm{H} / \mathrm{ACA}$ domain is important for RNA processing and RNA stability in vivo (Mitchell et al. 1999a,b; Martin-Rivera and Blasco 2001; Vulliamy et al. 2001).

Telomerase differs from other reverse transcriptases in that it contains an intrinsic RNA and uses only a small portion of it as the template. To precisely copy telomere sequence from only the template region of the RNA, the boundary of the template must be specifically defined. Structural elements that are important for template boundary definition have been identified in Tetrahymena and Kluyveromyces telomerase RNAs (Autexier and Greider 1995; Tzfati et al. 2000; Lai et al. 2002). Using telomerase reconstituted in vitro and in vivo and a conventional telomerase assay that measures products of telomerase elongation directly, we defined the RNA regions required for template boundary definition in human and mouse RNA.

Mutant telomere repeats do not bind the appropriate telomere proteins and have been shown to cause cell death in human cells (Kim et al. 2001). Disruption of the boundary function results in misincorporation of inappropriate nucleotides into telomeres and may reduce cellular viability and increase apoptosis. Therefore, the boundary-defining element of human telomerase could serve as an excellent target for drugs to inhibit cellular proliferation and tumor growth.

\section{Results and Discussion}

The elements responsible for template boundary definition in ciliate and yeast telomerase RNA are close to and upstream of the template sequence. However, no structure or sequence motif similar to these known structures is present in the vertebrate RNA. To determine if a region upstream of the template in mammalian telomerase RNA is important for boundary definition, we generated recombinant telomerase enzyme reconstituted in vitro and in vivo. In the in vitro reconstitution system, the TERT protein is expressed in rabbit reticulocyte lysate and assembled with in vitro transcribed telomerase RNA. For the in vivo reconstitution system, the TERT protein and telomerase RNA genes are coexpressed in telomerase-negative cells. The reconstituted telomerase was immunopurified and assayed for activity using a direct assay, which monitors telomere elongation at the single-nucleotide level (Chen and Greider 2003).

Template boundary definition in human telomerase

In the human telomerase RNA (hTR), helix P1 is the only conserved structural element located upstream of 
the template (Chen et al. 2000) and was thus a good candidate for defining the template boundary (Fig. 1A). This long-range base-paired structure is formed between a sequence near the $5^{\prime}$-end of the template and a sequence downstream of the pseudoknot domain. The helix P1 can be divided into two base-paired regions, helix P1a and P1b, which are separated by an internal loop (Fig. 1A).

To assess the importance of the helix P1 structure in telomerase function, we generated a variety of RNA truncation mutants with a $5^{\prime}$-end at positions $1,15,26$, 32 , or 44 , and with a $3^{\prime}$-end at position 212 . These mutant pseudoknot RNA fragments, which lack the 3 '-half of the RNA, were assembled in trans with the essential CR4-CR5 RNA fragment (nucleotides 242-328) and in vitro expressed TERT to reconstitute telomerase activity.

The RNA mutants, hTR1-212, hTR15-212, hTR26212 , or hTR32-212, reconstituted telomerase activity that showed a typical 6-nt repeat pattern of elongation products with major bands at positions $+4,+10,+16$, and +22 (Fig. 1B, lanes 1-4). The removal of the first 31 residues in the mutant hTR32-212 RNA resulted in an increase in the overall telomerase activity as previously reported (Beattie et al. 1998; Tesmer et al. 1999), which might be caused by altered folding of the mutant RNAs. Whereas the absence of helix P1a in this mutant hTR32212 did not alter the pattern of the repeats added, the lack of both P1a and P1b helices in the mutant hTR44212 resulted in additional bands at positions $+6,+12$,

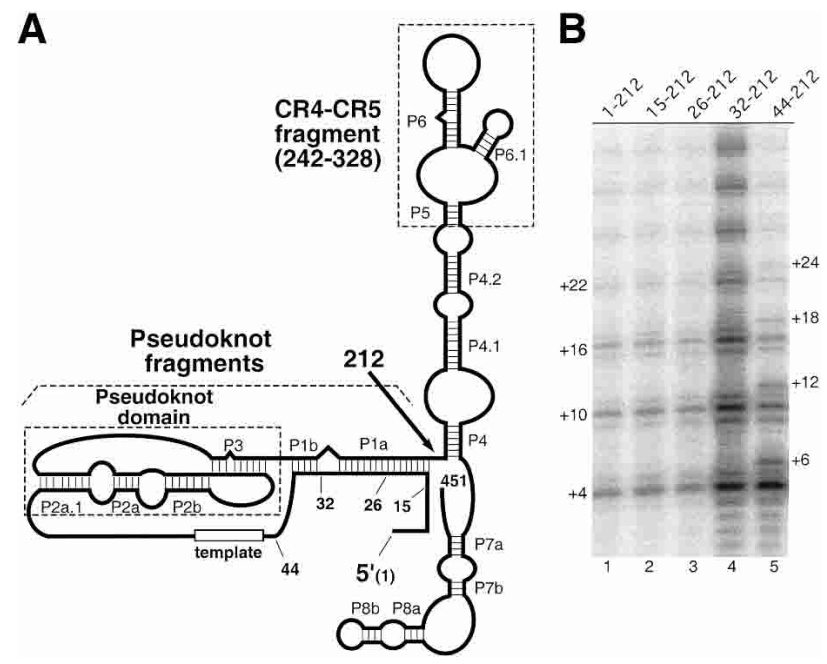

Figure 1. Effects of 5 -end truncation of hTR on telomerase activity. (A) Schematic diagram of the secondary structure of hTR. The nucleotide positions of the $5^{\prime}$-end $(1,15,26,32,44)$ and the $3^{\prime}$-end (212) of truncated RNA mutants are indicated. Each helical region is labeled as previously described (Chen et al. 2000, 2002). The RNA fragments, pseudoknot and CR4-CR5 fragments, used in the in vitro reconstitution of telomerase are indicated by a dashed bracket and a dashed box, respectively. The conserved pseudoknot structural domain is also indicated by a dashed box. $(B)$ Telomerase activity assay of telomerase reconstituted with the 5 '-truncated telomerase RNA fragments. The truncated RNA fragments, as indicated above each lane, were reconstituted with in vitro expressed hTERT-HA2 protein in the presence of the CR4-CR5 RNA fragment. Immunopurified enzyme was assayed for telomerase activity using telomere primer (TTAGGG) 3 in the presence of all four nucleotides (dNTPs). For each major band, the number of nucleotides added to the 3 '-end of the primer is indicated either on the left side $(+4,+10,+16,+22)$ or on the right side $(+6,+12,+18,+24)$ of the gel.
+18 , and +24 (Fig. 1B, cf. lanes 4 and 5). Because the 5 '-end of the hTR44-212 RNA is located only two residues upstream of the template (see Fig. 1A), the additional bands might have resulted from the utilization of the two residues at positions 44 and 45 as a template. These results indicate that the sequence or the structure of this region (nucleotides 32-43) plays an important role in human telomerase RNA function. Similar results were obtained using a single RNA fragment with the same 5 '-end truncation and a native 3 '-end (data not shown), indicating the two-RNA fragment reconstitution of telomerase did not alter normal telomerase function and the pseudoknot domain alone is responsible for the altered banding pattern of the hTR 5 '-end truncation mutants.

To further investigate the role of helix P1b in telomerase function, we generated pseudoknot RNA fragments with mutations that altered the sequence on either the bottom strand (hTR 32-195-ml) or the top strand (hTR 32-195-m2) of helix P1b, and a double mutant that restored base pairing for the helix P1b (hTR 32-195-m3). In addition, we generated a mutant (hTR 32-195-m4) in which the sequence of the unpaired region located downstream of helix P1 was changed from 38-UUUUUU-43 to 38-AAAAAA-43 (Fig. 2A). Disruption of the P1b pairing in both the mutants hTR 32-195$\mathrm{m} 1$ and hTR $32-195-\mathrm{m} 2$ resulted in a reduction of overall activity and an abnormal pattern of telomere products (Fig. 2A, lanes 3,4). Restoration of the P1b base pairing in the mutant hTR 32-195-m3 fully restored telomerase activity (Fig. 2A, lane 5). Alteration of the sequence in the single-stranded region 38-UUUUUU-43 did not change the level of activity or the pattern of elongation products (Fig. 2A, lane 6). Therefore, the base-paired structure of helix P1b, but not the adjacent sequence, is essential for correct utilization of the template.

We predicted that the altered pattern of telomere products seen in all of the mutants that lacked the helix P1b resulted from read-through polymerization past the end of the normal template and incorporation of nontelomeric sequence to telomere products. To test this, we generated RNA mutants that either have or lack the helix P1b (Fig. 2B) and assayed for telomerase activity in the presence or absence of dCTP. The change in the elongation pattern of products in the presence or absence of $\mathrm{dCTP}$ indicates the use of the $\mathrm{G}$ residues as template past the normal boundary. In the mutant hTR 32-195$\mathrm{m} 2$, which lacked helix P1b, a strong band at position +5 was seen in the absence of dCTP, indicating copying of the nontemplate residue $\mathrm{U} 45$. Incorporation stops here because using the next residue G44 as a template requires dCTP (Fig. 2B, lane 3). The banding pattern of telomere products was changed in the presence of dCTP (Fig. 2B, lane 4), indicating that dCTP was incorporated into products using the G44 as a template. Thus, the changed pattern of telomere products resulted from the usage of sequence beyond the normal template boundary. To confirm that the G44 residue was responsible for generating the strong band at +5 in the absence of dCTP, we generated the mutant RNA 32-195-m5b, which had the G44 residue moved to position 38 located further upstream of the template. Interestingly, in the absence of dCTP, the enzyme reconstituted with this mutant RNA, hTR 32-195-m5b, gave strong bands not only at position +5 , but also at positions $+6,+7,+8$, and +9 , suggesting copying of template past the residue 44 (Fig. $2 B$, cf. lanes 
A

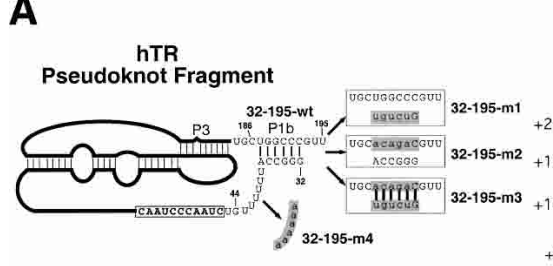

B
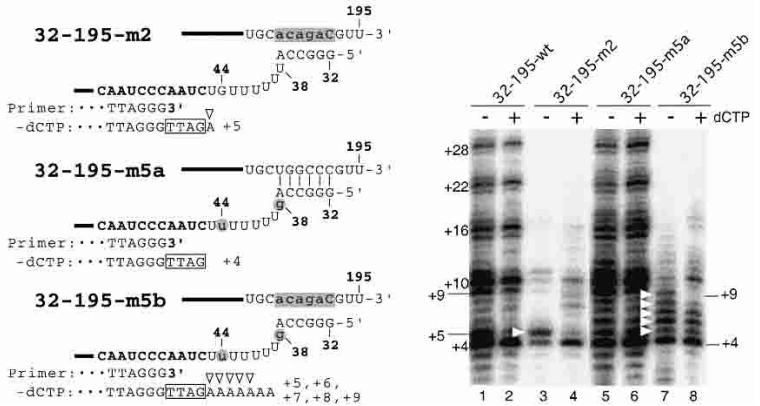

Figure 2. Effects of mutations in the P1b helix of hTR on telomerase template boundary definition. $(A$, left $)$ Schematic diagram of the mutant hTR pseudoknot fragments. The regions altered in each pseudoknot mutant are shaded, and the sequences changed are shown in lowercase. (Right) Telomerase activity assay with in vitro reconstituted telomerase containing the P1b mutant RNAs. Each pseudoknot RNA fragment with a Plb mutation, as indicated above each lane, was reconstituted with hTERT-HA2 protein and an hTR CR4-CR5 RNA fragment. Immunopurified enzyme was assayed for telomerase activity in the presence of all four nucleotides (dNTPs). $(B$, left $)$ Schematic diagram of the mutant hTR pseudoknot fragments. The regions altered in each pseudoknot mutant are shaded, and the sequences changed are shown in lowercase. The primer sequence is aligned with the RNA template sequence that is shown in bold. Nucleotides in the boxes represent nucleotides added to the $3^{\prime}$-end of primers. Open triangles indicate nucleotides added with nontelomeric sequence. (Right) Telomerase activity assay of in vitro reconstituted telomerase containing mutant telomerase RNA fragments. Reconstituted enzyme was assayed for telomerase activity in either the absence or the presence of $0.5 \mathrm{mM} \mathrm{dCTP}$. White triangles indicate bands of read-through product with nontelomeric nucleotides incorporated.

3 and 7). The presence of strong bands at positions $+5,+6$, $+7,+8$, and +9 , but not at position +11 , suggests pausing of the polymerization at residues $\mathrm{U} 45, \mathrm{U} 44, \mathrm{U} 43, \mathrm{U} 42$, and U41, before reaching the G38 residue. Furthermore, the increased mobility of bands generated by the 32-195$\mathrm{m} 5 \mathrm{~b}$ mutant compared with wild type suggests that a different sequence is added to the mutant products (Fig. 2B, cf. lanes 5 and 7). For those RNAs with a stable P1b helix, no difference in the pattern of telomere products was seen in either the presence or absence of dCTP (Fig. $2 \mathrm{~B}$, lanes $1,2,5,6)$. Therefore, the base-paired structure of P1b helix defines the template boundary, but the sequence of the helix and the linker region is not important.

To understand how the helix P1b defines the template boundary, we tested if the length of the linker region between the template and the helix P1b is critical for defining the correct template boundary. We generated RNA mutants, hTR 32-195(+1U) and hTR 32-195(+2U), that had one or two nucleotide insertions in the singlestranded uridine U-tract region adjacent to the helix P1b (Fig. 3A). Telomerase reconstituted in vitro using the RNA mutant hTR 32-195(+2U) showed a series of three bands above the major band at +4 upon addition of dCTP (Fig. 3B, lanes 5,6). The enzyme reconstituted using mutant hTR 32-195(+1U) showed an additional band only at +5 (Fig. 3B, lanes 3,4). To examine whether these results using in vitro reconstituted enzyme were reproducible with in vivo reconstituted telomerase holoenzyme, we coexpressed the hTERT-HA protein and full-length hTR genes in the telomerase-negative VA13 cells. The in vivo reconstituted telomerase mutant with a two U-residue insertion in the RNA, analogous to the hTR 32-195(+2U) mutant, showed additional bands at positions $+5,+6$, and +7 upon addition of dCTP (Fig. 3C, lanes 7,8). This result is consistent with the in vitro results and indicates that although the sequence of the linker region is not important, increasing the distance between the helix P1b and the template interferes with template boundary definition. The enzyme reconstituted in vivo using phTR $(\mathrm{m} 2)$ with mutations that disrupt helix P1b generated weak activity and shown altered telomere pattern (Fig. 3C,

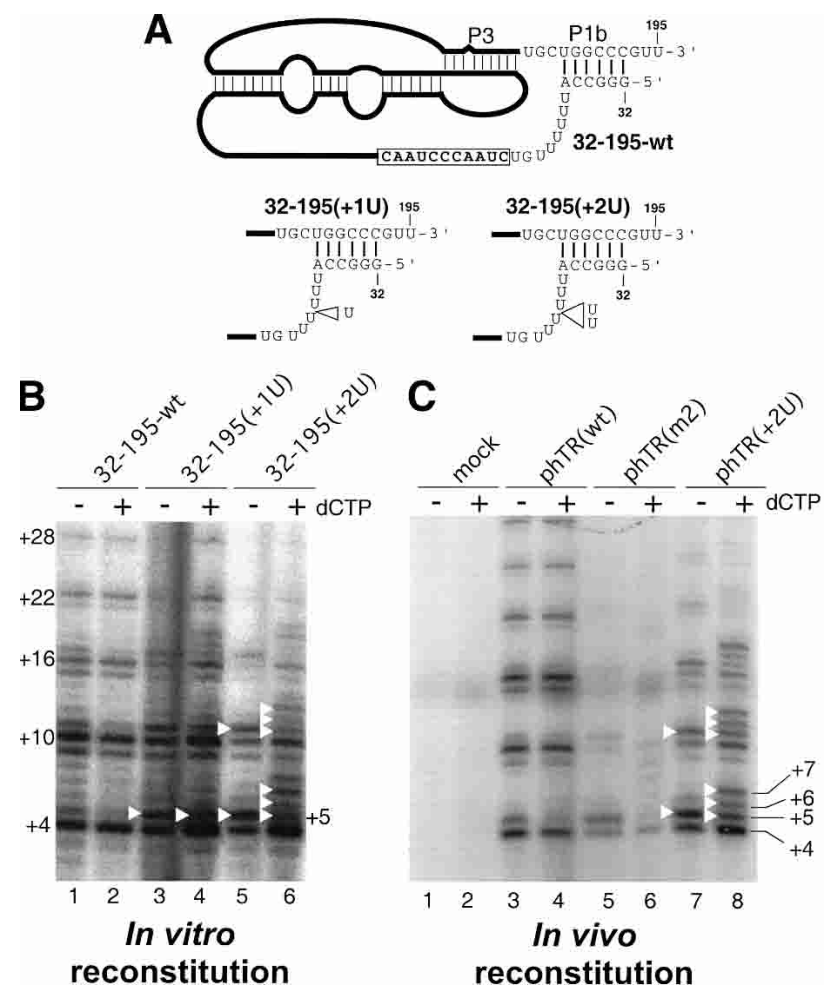

Figure 3. Effects of altered linker length between the P1b helix and the template on template boundary definition. $(A)$ Schematic diagram of the mutant hTR pseudoknot fragments. The U-residue insertions made in the pseudoknot mutants, 32-195(+1U) and 32$195(+2 \mathrm{U})$, are indicated by open triangles. $(B)$ Telomerase activity assay of in vitro reconstituted telomerase containing the linkerlength mutant RNAs. Various pseudoknot RNA fragmentshTR32-195-wt, hTR32-195(+1U), and hTR32-195(+2U)-were assembled with hTR-CR4-CR5 RNA and in vitro expressed hTERTHA protein. In vitro reconstituted enzyme was immunopurified and assayed for activity. The activity assay was carried out in either the absence or the presence of $0.5 \mathrm{mM}$ dCTP. Bands representing incorporation past the normal template are marked with white triangles. (C) Telomerase activity assay of in vivo reconstituted human mutant telomerase. The telomerase RNA genes are expressed in vivo from $\operatorname{phTR}(\mathrm{wt}), \operatorname{phTR}(\mathrm{m} 2)$, or $\operatorname{phTR}(+2 \mathrm{U})$, as indicated above the gel. A mock transfection with only phTERT-HA was included to ensure the absence of endogenous hTR expression (lanes 1,2). 
lanes 5,6 ), as did the in vitro reconstituted enzyme (Fig. $2 \mathrm{~B}$, lanes 3,4$)$. The weak activity of this mutant suggests that the disruption of helix P1b might also interfere with telomerase RNA folding and/or RNP assembly both in vitro and in vivo. We conclude that helix P1b defines the template boundary by maintaining an appropriate linker length between the anchored $\mathrm{P} 1 \mathrm{~b}$ helical region and the template. This single-stranded linker region might provide flexibility for template movement within the active site of TERT during telomere elongation.

\section{Template boundary definition in mouse telomerase}

In contrast to the human telomerase RNA, the mouse telomerase RNA has a $5^{\prime}$-end located only 2 nt upstream of the template (Hinkley et al. 1998) and thus lacks the helix P1 that is conserved in most vertebrate telomerase RNAs (Chen et al. 2000). To test the effect of the $5^{\prime}$-end position of $\mathrm{mTR}$ on template boundary definition, we generated mutant mTR fragment with extensions at the 5 '-end; mTR(-2g)-155 has two additional residues and $\operatorname{mTR}(-4 \mathrm{~g})-155$ has four additional residues at the $5^{\prime}$-end. The $5^{\prime}$-end of mutant $\mathrm{mTR}(+1 \mathrm{~g})-155$ is identical to that of wild-type mTR except the first residue was changed from adenine to guanosine for efficient in vitro $\mathrm{T} 7$ synthesis of the RNA. This $5^{\prime}$-end G residue was also used to monitor the template usage in the presence of dCTP.

Telomerase activity reconstituted from the $\mathrm{mTR}(+1 \mathrm{~g})$ 155, $\operatorname{mTR}(-2 \mathrm{~g})-155$, and $\mathrm{mTR}(-4 \mathrm{~g})-155$ mutants showed additional bands upon the addition of dCTP (Fig. 4A, arrows in lanes $2,4,6$ ). This result indicates that these recombinant mouse telomerase enzymes copy sequence beyond the normal template boundary up to the $\mathrm{G}$ residue at the $5^{\prime}$-end (Fig. 4A). Consistent with the incorporation of nontelomeric sequence into the telomere products, the mutant RNAs mTR(-2g)-155 and $\operatorname{mTR}(-4 \mathrm{~g})$ 155 were less processive than wild-type RNA (Fig. 4A, lanes $1,4,6)$. This also suggests that incorporation of nontelomeric sequence inhibits repositioning after translocation. Therefore, in the absence of helix P1, the presence of a $5^{\prime}$-end closer to the template can limit template read-through. This may explain why the $5^{\prime}$-end is so close to the template region in $\mathrm{mTR}$ and other rodent telomerase RNAs (Chen et al. 2000).

In addition, to test if an artificial helix P1b structure could function as a template boundary element in mouse telomerase, we generated an RNA mutant, $\operatorname{mTR}(-13)$ 155(P1), with a 13-nt extension at the 5 '-end to introduce an artificial helical structure that mimics the typical helix P1b of other vertebrate telomerase RNAs. This mutant showed a wild-type banding pattern, and there was no change upon the addition of dCTP (Fig. 4A, lanes 7,8). Thus, the introduction of helix $\mathrm{P} 1 \mathrm{~b}$ prevents the enzyme from reading through the normal template boundary. This mutant, $\operatorname{mTR}(-13)-155(\mathrm{P} 1)$, also showed increased processivity (Fig. 4A, lanes 1,7), suggesting that the helix P1b provides an optimal RNA structure for telomerase function. Sequence alignment and RNA secondary structure show that the helix P1 is present in all known vertebrate telomerase RNAs, except mouse, rat, and hamster (Chen et al. 2000). This suggests a loss of the functional helix P1 in the rodent lineage during evolution.

A 5'-2,2,7-trimethyl-quanosine cap is present on yeast telomerase RNA and is likely present on mammalian telomerase RNAs, which is also transcribed by RNA polymerase II (Avilion 1995; Seto et al. 1999). Thus, the
A

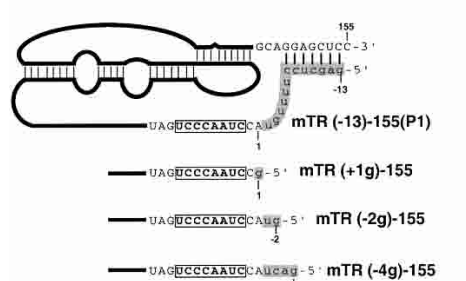

B
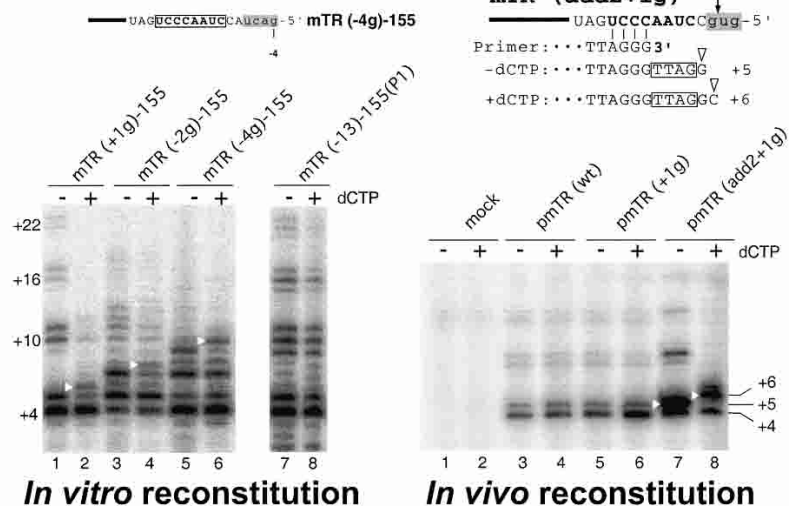

Figure 4. Effects of $5^{\prime}$-end extension of mouse telomerase RNA on telomerase template boundary definition. (A) Analysis of in vitro reconstituted mouse telomerase. (Top) Schematic diagram of the mutant mTR pseudoknot fragments used in the in vitro reconstitution. The sequence changed at the $5^{\prime}$-end of each RNA mutant$\operatorname{mTR}(+1 \mathrm{~g})-155, \operatorname{mTR}(-2 \mathrm{~g})-155, \operatorname{mTR}(-4 \mathrm{~g})-155$, and $\operatorname{mTR}(-13)-$ 155(P1) - is shaded. (Bottom) Direct activity assay of in vitro reconstituted mouse telomerase. Each pseudoknot RNA fragment with either a $5^{\prime}$-end extension or the artificial P1b helix was reconstituted with the mTERT-HA2 protein and the mTR CR4-CR5 RNA fragment, and assayed for activity in the presence or absence of dCTP. (B) Analysis of in vivo reconstituted mouse telomerase. (Top) Sequence at the $5^{\prime}$-end of the mTR mutants. The sequence changed at the $5^{\prime}$-end of each RNA mutant-mTR $(+1 \mathrm{~g})$ and $\mathrm{mTR}(\operatorname{add} 2+1 \mathrm{~g})$ - is shaded. The template boundary located 2 nt downstream of the 5 '-end is indicated with an arrow. The primer sequence is aligned with the RNA template sequence that is shown in bold. Nucleotides in the box represent nucleotides added at the $3^{\prime}$-end of primers. Open triangles indicate nucleotides added past the normal boundary. (Bottom) Direct activity assay of in vivo reconstituted mouse telomerase with the mTR mutant. Mouse telomerase RNAs were expressed from pmTR(wt), pmTR $(+1 \mathrm{~g})$, and $\operatorname{pmTR}(\operatorname{add} 2+1 \mathrm{~g})$, and reconstituted with mTERT-HA protein in mTR-deficient mouse embryonic fibroblast cells. The reconstituted enzyme was immunopurified and assayed for telomerase assay in the presence or absence of dCTP. The number of nucleotides added at the major bands is marked on the right of the gel.

presence of two nucleotides at the 5 '-end adjacent to the template in the rodent telomerase RNA might be required to compensate for a possible steric effect caused by the $5^{\prime}$-cap structure, and to allow accurate utilization of the RNA template in vivo. To test this hypothesis, we expressed a mutant $m T R$ gene in a mTR-deficient mouse embryonic fibroblast cell line (Blasco et al. 1997); the reconstituted enzyme was immunopurified, and activity was assayed directly. Interestingly, in contrast to the enzyme reconstituted in vitro with $\mathrm{mTR}(+1 \mathrm{~g})-155$ RNA, the in vivo reconstituted enzyme using either $\mathrm{mTR}(+1 \mathrm{~g})$ or the wild-type MTR generated identical banding patterns in the presence or absence of dCTP (Fig. 4B, lanes $3-6)$, and therefore the first two residues at the $5^{\prime}$-end were not used as a template. In contrast, the mutant RNA, mTR $(\operatorname{add} 2+1 \mathrm{~g})$, with four nucleotides upstream of the template at the $5^{\prime}$-end showed a strong band at po- 
sition +5 in the absence of dCTP indicative of usage of the residue $4 \mathrm{C}$ as a template (Fig. $4 \mathrm{~B}$, lane 7 ). In the presence of dCTP, a strong band was seen at position +6 , indicating that the residue $\mathrm{G} 3$, but not the residues $\mathrm{U} 2$ and G1, was used as a template (Fig. 4B, lane 8). The 5 '-ends of the in vivo expressed RNAs were mapped using RNA ligase-mediated rapid amplification of cDNA ends (RLM-RACE), and the sequence showed that the expected 5'-ends were present (Fig. 4B; data not shown). These results indicate that in vivo expressed mouse telomerase has the template boundary defined at the position $2 \mathrm{nt}$ downstream of the $5^{\prime}$-end.

\section{Diversity of template boundary definition in telomerase}

Template boundary definition is a unique feature for telomerase enzymes among reverse transcriptase enzymes. Although telomerase RNA structure plays essential roles in defining the template boundary in different species (Autexier and Greider 1995; Tzfati et al. 2000; Lai et al. 2002), the specific structures that are used are surprisingly divergent (Fig. 5A).

In yeast, a base-paired structure upstream of the RNA template plays a role in template boundary definition

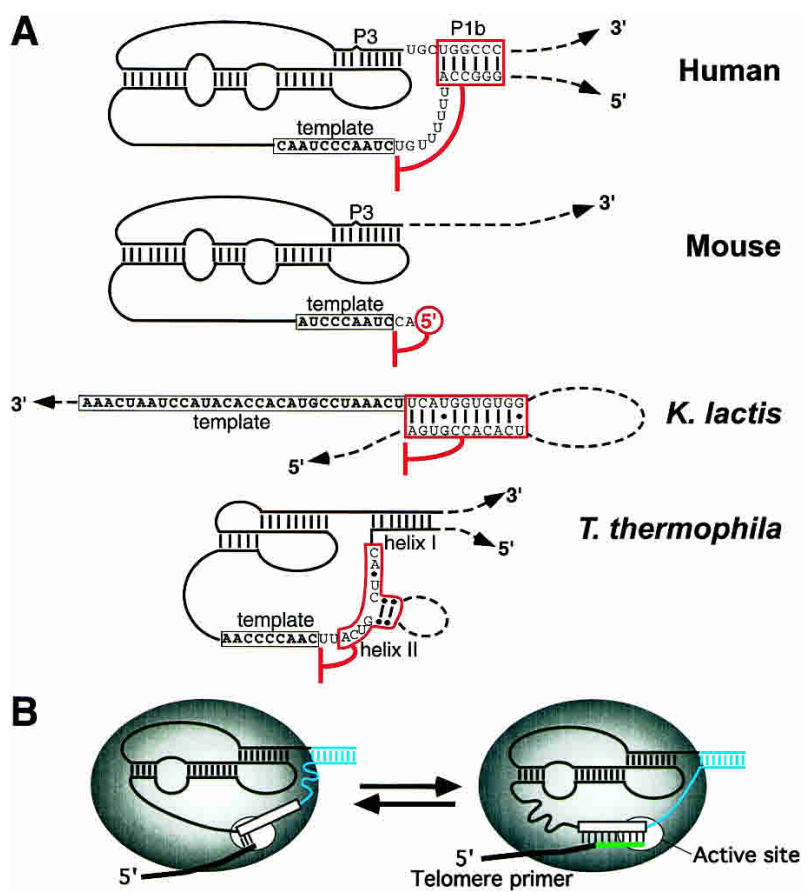

Figure 5. (A) Comparison of template boundary definition elements among human, mouse, yeast, and ciliate telomerase RNAs. The known secondary structures of regions flanking the RNA template are depicted for human, mouse, Kluyveromyces lactis (yeast), and Tetrahymena thermophila (ciliate) telomerase RNAs. The sequence of the template region is shown in a black box, and the RNA structure essential for template boundary definition is shown in a red box with a red line to indicate function in boundary definition. (B) A proposed model for template boundary definition in human telomerase. The TERT protein is depicted as a gray sphere with the catalytic site shown as an open circle. The helix P1b (shown in blue) serves as an anchor point for tethering the linker (shown in blue) and the template region (white box). During the copying of the template, the movement of the RNA template within the catalytic site is constrained by the length of the linker region.
(Fig. 5A). This structural element in yeast is different from that described here for hTR. First, it is located immediately next to the template, whereas the human structure is $8 \mathrm{nt}$ upstream of the template. Second, the yeast structure is formed by two regions both located upstream of the template, whereas the human structure is formed by one region located upstream of the template and one region located downstream of the pseudoknot domain. Because of these structural differences, yeast and human telomerase likely use different mechanisms to define the template boundary.

In contrast to the vertebrate and yeast RNAs, ciliate telomerase defines the template boundary through the sequence and location of a conserved sequence motif located upstream of the template (Lingner et al. 1994; Autexier and Greider 1995). This highly conserved RNA motif is a binding site for the TERT protein (Lai et al. 2002), and the linker length between this conserved motif and template is important for template boundary definition in Tetrahymena telomerase (Autexier and Greider 1995). The RNA motif required for template boundary definition in Tetrahymena telomerase is quite different from the helix P1b of vertebrate RNA in several aspects. First, the RNA motif in Tetrahymena is highly conserved in sequence, but not the secondary structure, whereas the helix P1b is conserved in secondary structure, but not in primary sequence (Fig. 5A). Although there is a helical region associated with this sequence motif in many ciliates, this helix II is absent in Tetrahymena paravorax (McCormick-Graham and Romero 1995). Second, the Tetrahymena element is important for TERT binding, whereas the helix P1b is not essential for TERT binding to the human pseudoknot RNA fragment (Chen and Greider 2003). Therefore, it seems unlikely that helix P1b functions as a boundary-defining element through sequence-specific RNA-protein recognition. However, a nonspecific RNA-protein interaction is not ruled out.

Despite the structural difference, ciliate and human telomerase RNAs may share a mechanism for defining the template boundary. Both ciliate and human elements may establish the template boundary by constraining the movement of the RNA template within the catalytic active site of TERT protein through either RNA-protein interaction or RNA-RNA base-pairings (Fig. 5B). In contrast, the yeast element may define the template boundary by limiting the availability of the single-stranded region adjacent to the template. The fact that these species use different RNA structural features in defining the template boundary highlights the significant divergence of the telomerase RNA components.

\section{Materials and methods}

Reconstitution of telomerase

Human and mouse telomerase complexes were reconstituted either in vitro or in vivo as described previously (Chen and Greider 2003). For in vitro reconstitution of telomerase, the RNA gene was PCR-amplified from plasmids containing either $h T R$ or $m T R$ genes using oligonucleotides with the desired sequence changes to introduce specific mutations. Telomerase RNAs were generated by $\mathrm{T} 7$ in vitro transcription using PCR DNA templates. Epitope-tagged human and mouse TERT proteins were expressed from phTERT-HA2 and pmTERT-HA2 (Chen and Greider 2003) using the TnT transcription/translation system (Promega). For in vivo reconstitution of telomerase, the HA-tagged mTERT gene and the genomic copy of mTR genes $\operatorname{pmTR}(w t), \operatorname{pmTR}(+1 \mathrm{~g})$, and $\operatorname{pmTR}(\operatorname{add} 2+1 \mathrm{~g})$ were expressed in mTR-deficient mouse embryonic fibroblast cells, 
whereas the hTERT-HA and hTR genes were expressed in the VA13 cells, a human telomerase-negative cell line. Reconstituted telomerase complexes were affinity-purified using anti-HA F7 agarose beads (Santa Cruz Biotechnology), and assayed for telomerase activity.

\section{Direct telomerase assay}

Activity of immunopurified telomerase was assayed directly without amplification (Chen and Greider 2003). The reaction mixture $(20 \mu \mathrm{L})$ contained $1 \times$ telomerase assay buffer $(50 \mathrm{mM}$ Tris- $\mathrm{HCl}$ at $\mathrm{pH} 8.0,50 \mathrm{mM}$ $\mathrm{KCl}, 1 \mathrm{mM} \mathrm{MgCl} 2,5 \mathrm{mM} \beta$-mercaptoethanol, and $1 \mathrm{mM}$ spermidine), 1.0 $\mu \mathrm{M}$ telomere primer (TTAGGG)3, $0.5 \mathrm{mM}$ dATP, $0.5 \mathrm{mM}$ dTTP, $2 \mu \mathrm{M}$ dGTP, and $1.25 \mu \mathrm{M}\left[\alpha{ }^{32} \mathrm{P}\right] \mathrm{dGTP}(800 \mathrm{Ci} / \mathrm{mmole})$ with $6 \mu \mathrm{L}$ of immunopurified telomerase complex. To monitor the template utilization, 0.5 $\mathrm{mM}$ dCTP was included in some reactions as indicated. The reaction was incubated at $30^{\circ} \mathrm{C}$ for $1 \mathrm{~h}$. The products were ethanol-precipitated, followed by electrophoresis.

\section{Acknowledgments}

We thank Rachel Green, Doug Mason, Arne IJpma, and members of the Greider lab for helpful discussion on the manuscript. This research was funded by a grant from the National Institutes of Health (AG09383) to C.W.G. J.-L.C. is a fellow of the Leukemia \& Lymphoma Society.

The publication costs of this article were defrayed in part by payment of page charges. This article must therefore be hereby marked "advertisement" in accordance with 18 USC section 1734 solely to indicate this fact.

\section{References}

Autexier, C. and Greider, C.W. 1995. Boundary elements of the Tetrahymena telomerase RNA template and alignment domains. Genes \& Dev. 9: 2227-2239.

Avilion, A.A. 1995. Characterization and expression of human telomerase. In Graduate Program in Cellular and Developmental Biology, pp. 234. State University of New York at Stony Brook, Stony Brook, NY.

Beattie, T.L., Zhou, W., Robinson, M.O., and Harrington, L. 1998. Reconstitution of human telomerase activity in vitro. Curr. Biol. 8: $177-180$.

Blasco, M.A., Lee, H.W., Hande, M.P., Samper, E., Lansdorp, P.M., DePinho, R.A., and Greider, C.W. 1997. Telomere shortening and tumor formation by mouse cells lacking telomerase RNA. Cell 91: 25-34.

Bryan, T.M., Goodrich, K.J., and Cech, T.R. 2000. Telomerase RNA bound by protein motifs specific to telomerase reverse transcriptase. Mol. Cell 6: 493-499.

Chen, J.-L. and Greider, C.W. 2003. Determinants in mammalian telomerase RNA that mediate enzyme processivity and cross-species incompatibility. EMBO J. 22: 304-314.

Chen, J.-L., Blasco, M.A., and Greider, C.W. 2000. Secondary structure of vertebrate telomerase RNA. Cell 100: 503-514.

Chen, J.-L., Opperman, K.K., and Greider, C.W. 2002. A critical stemloop structure in the CR4-CR5 domain of mammalian telomerase RNA. Nucleic Acids Res. 30: 592-597.

Greider, C.W. 1996. Telomere length regulation. Annu. Rev. Biochem. 65: 337-365.

Greider, C.W. and Blackburn, E.H. 1985. Identification of a specific telomere terminal transferase activity in Tetrahymena extracts. Cell 43: 405-413.

- 1989. A telomeric sequence in the RNA of Tetrahymena telomerase required for telomere repeat synthesis. Nature 337: 331-337.

Hinkley, C.S., Blasco, M.A., Funk, W.D., Feng, J., Villeponteau, B., Greider, C.W., and Herr, W. 1998. The mouse telomerase RNA 5'-end lies just upstream of the telomerase template sequence. Nucleic Acids Res. 26: 532-536.

Kim, M.M., Rivera, M.A., Botchkina, I.L., Shalaby, R., Thor, A.D., and Blackburn, E.H. 2001. A low threshold level of expression of mutanttemplate telomerase RNA inhibits human tumor cell proliferation. Proc. Nat1. Acad. Sci. 98: 7982-7987.

Kim, N.W., Piatyszek, M.A., Prowse, K.R., Harley, C.B., West, M.D., Ho, P.L., Coviello, G.M., Wright, W.E., Weinrich, S.L., and Shay, J.W. 1994. Specific association of human telomerase activity with immortal cells and cancer. Science 266: 2011-2015.
Lai, C.K., Mitchell, J.R., and Collins, K. 2001. RNA binding domain of telomerase reverse transcriptase. Mol. Cell. Biol. 21: 990-1000.

Lai, C.K., Miller, M.C., and Collins, K. 2002. Template boundary definition in Tetrahymena telomerase. Genes \& Dev. 16: 415-420.

Lingner, J., Hendrick, L.L., and Cech, T.R. 1994. Telomerase RNAs of different ciliates have a common secondary structure and a permuted template. Genes \& Dev. 8: 1984-1998.

Lingner, J., Hughes, T.R., Shevchenko, A., Mann, M., Lundblad, V., and Cech, T.R. 1997. Reverse transcriptase motifs in the catalytic subunit of telomerase. Science 276: 561-567.

Martin-Rivera, L. and Blasco, M.A. 2001. Identification of functional domains and dominant negative mutations in vertebrate telomerase RNA using an in vivo reconstitution system. J. Biol. Chem. 276: 5856-5865.

McCormick-Graham, M. and Romero, D.P. 1995. Ciliate telomerase RNA structural features. Nucleic Acids Res. 23: 1091-1097.

Mitchell, J.R. and Collins, K. 2000. Human telomerase activation requires two independent interactions between telomerase RNA and telomerase reverse transcriptase. Mol. Cell 6: 361-371.

Mitchell, J.R., Cheng, J., and Collins, K. 1999a. A box H/ACA small nucleolar RNA-like domain at the human telomerase RNA 3' end. Mol. Cell. Biol. 19: 567-576.

Mitchell, J.R., Wood, E., and Collins, K. 1999b. A telomerase component is defective in the human disease dyskeratosis congenita. Nature 402: 551-555.

Romero, D.P. and Blackburn, E.H. 1991. A conserved secondary structure for telomerase RNA. Cell 67: 343-353.

Seto, A.G., Zaug, A.J., Sobel, S.G., Wolin, S.L., and Cech, T.R. 1999. Saccharomyces cerevisiae telomerase is an Sm small nuclear ribonucleoprotein particle. Nature 401: 177-180.

Tesmer, V.M., Ford, L.P., Holt, S.E., Frank, B.C., Yi, X., Aisner, D.L., Ouellette, M., Shay, J.W., and Wright, W.E. 1999. Two inactive fragments of the integral RNA cooperate to assemble active telomerase with the human protein catalytic subunit (hTERT) in vitro. Mol. Cell. Biol. 19: 6207-6216.

Tzfati, Y., Fulton, T.B., Roy, J., and Blackburn, E.H. 2000. Template boundary in a yeast telomerase specified by RNA structure. Science 288: $863-867$.

Vulliamy, T., Marrone, A., Goldman, F., Dearlove, A., Bessler, M., Mason, P.J., and Dokal, I. 2001. The RNA component of telomerase is mutated in autosomal dominant dyskeratosis congenita. Nature 413: $432-435$.

Vulliamy, T., Marrone, A., Dokal, I., and Mason, P.J. 2002. Association between aplastic anaemia and mutations in telomerase RNA. Lancet 359: 2168-2170.

Weinrich, S.L., Pruzan, R., Ma, L., Ouellette, M., Tesmer, V.M., Holt, S.E., Bodnar, A.G., Lichtsteiner, S., Kim, N.W., Trager, J.B., et al. 1997. Reconstitution of human telomerase with the template RNA component hTR and the catalytic protein subunit hTRT. Nat. Genet. 17: 498-502. 


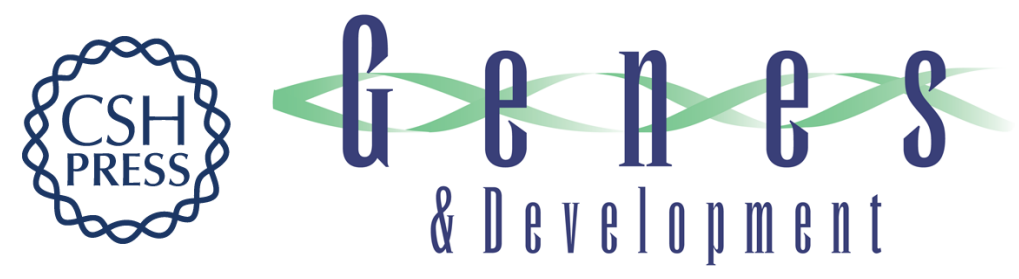

\section{Template boundary definition in mammalian telomerase}

Jiunn-Liang Chen and Carol W. Greider

Genes Dev. 2003, 17:

Access the most recent version at doi:10.1101/gad.1140303

References This article cites 29 articles, 12 of which can be accessed free at: http://genesdev.cshlp.org/content/17/22/2747.full.html\#ref-list-1

License

Email Alerting Receive free email alerts when new articles cite this article - sign up in the box at the top Service right corner of the article or click here.

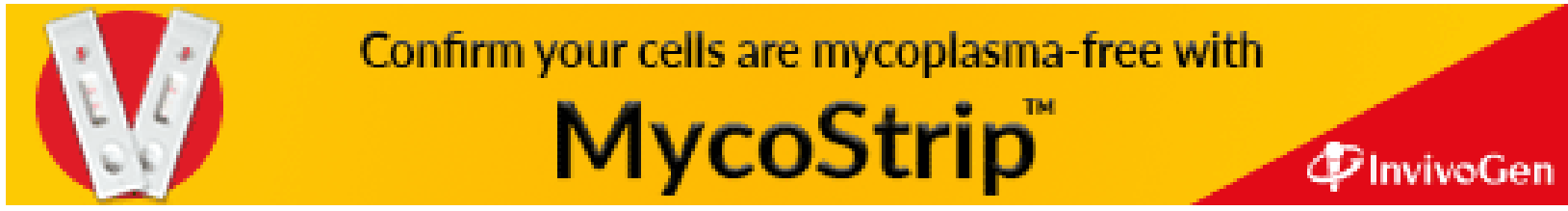

